\title{
LATE BLANCAN GAZELLE-HORSE NANNIPPUS PENINSULATUS (MAMMALIA, EQUIDAE) FROM SCURRY COUNTY, TEXAS, WITH IMPLICATIONS FOR BIOCHRONOLOGY
}

\section{Abstract}

Ongoing excavations at Roland Springs Ranch Localit 1 (RSR-1) in Scurry County, Texas, have produced vertebrate life. Remains of small, tridactys lequids are
vere most common large mammal in the RSR-1 fasme understanding these diminutive horses is important to determining paleo-community composition. Further, dentification of horse remains is biochronologically placing the RSR-1 fauna in time is depmederts,

faunal correlation. Ongoing biochronology research is

focused on seven taxa, one of which is the small hors The RSR-1 small horse remains are identified as

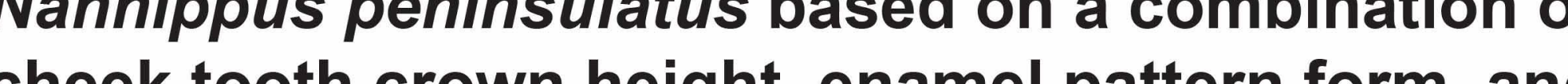
metapodial size. Highly cursorial with strongly hypsodont cheek teeth, $N$. peninsulatus is derived in it adaptations to open grassland. An enigmatic precursor, w. beenensis, is known only trom the late Pliocene locally or Bech Ranch, also in Scurry County. less advanced $N$. beckensis by increased crown height absence of protostylids, and increased metapodial elongation. Nannippus peninsulatus is characteristic of Mammal Age) fien of North Americe The Landico of N. peninsulatus at RSR-1 provides temporal separation trom Beck Ranch, and indicates an age of less than -3.5 milion years ago. Although not conclusive, this research of an earliest Pleistocene age for the RSR-1 fauna

\section{Introduction}

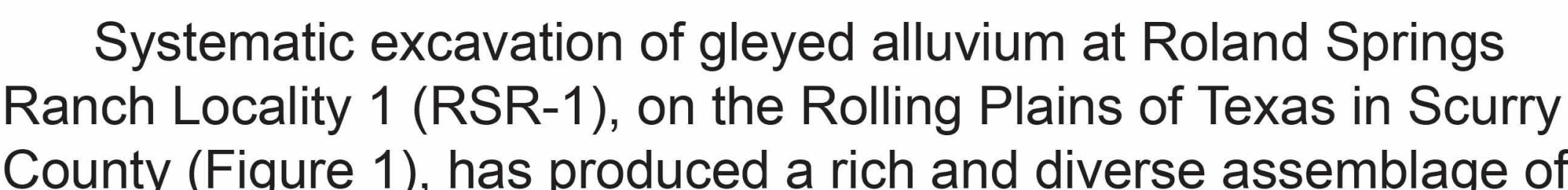
County (Figure 1) has produced a rich and diverse assemblage of
late Blancan Land Mammal Agev vertebratetes. The most conmon

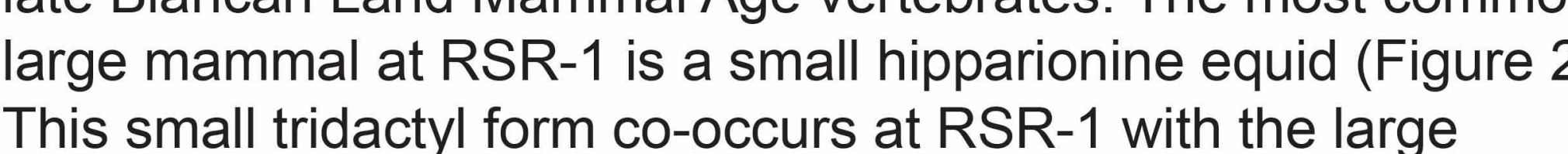

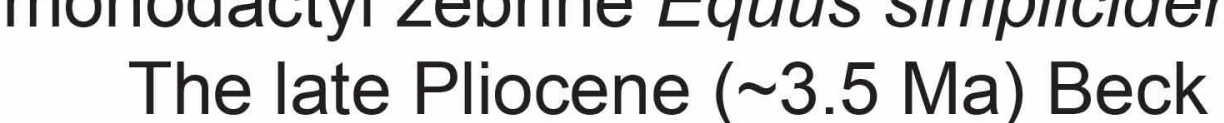
Scurry County (Dalquest. 1978). This fannh ancina is alsos fortor known only and a smal hidacyly form, Nannippus beckenss,

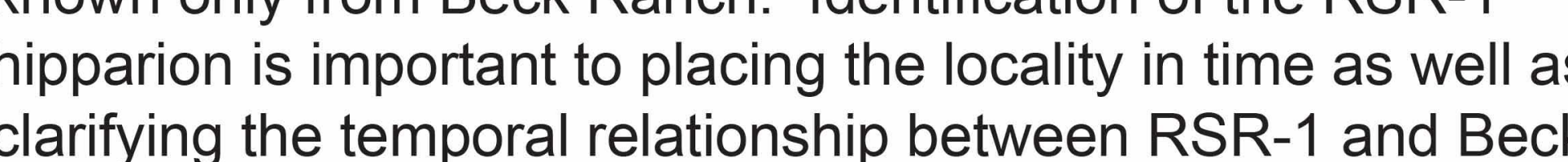

\section{Materials \& Methods} The RSR-1 hipparion sample of cheerk teeth $(n=79)$, mandibles
$(n=2)$, and metapodials $(n=6)$ was analyzyed to determinine a species

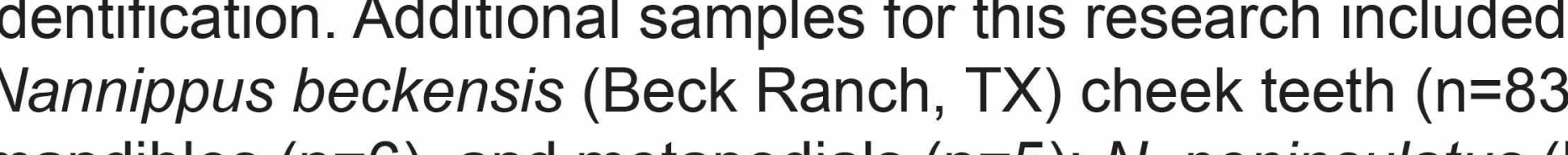

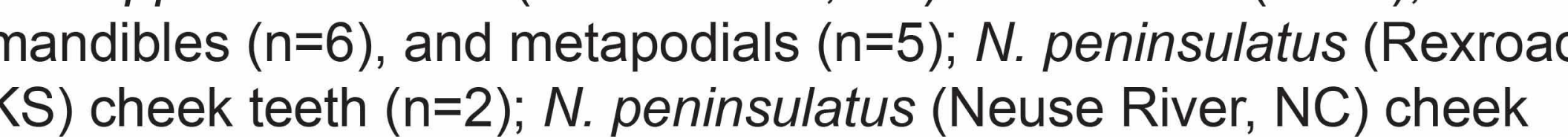

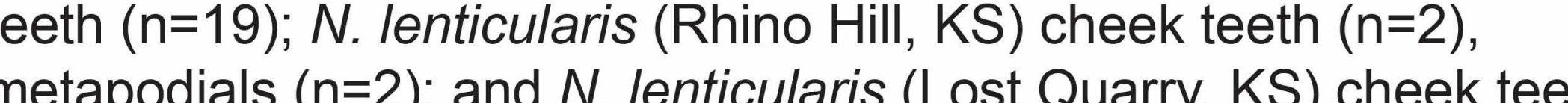

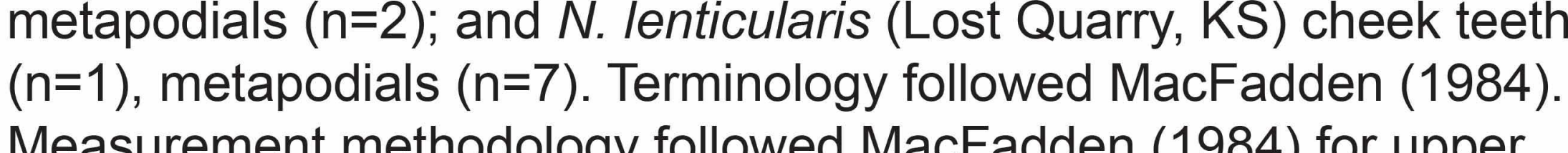
Measurement methodology y followed MacF adden (199d)
cheek teeth and Hubert $(1987$ ) for lower cheek teeth
John A. Moretti and Eileen Johnson Museum of Texas Tech University
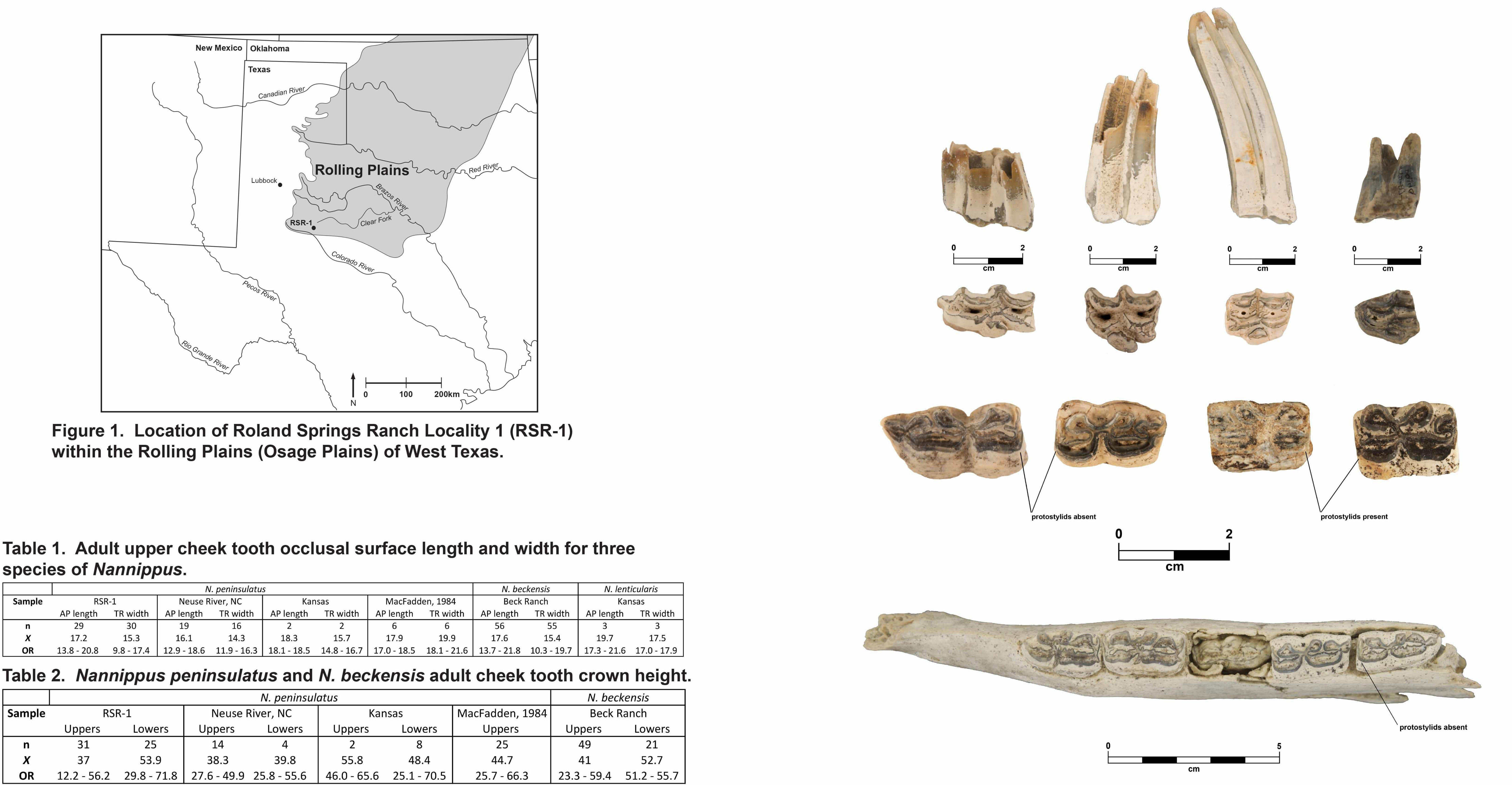

\section{Results}

epresented by deciduous, unworn/unerrupted adult, and lightly to heavily individuals, based on Mss, were recorded in the RSR-1 sample.
Addult RSR-1 upper cheek teeth ( $n=31$ ) exhibited (relative to ot equids) small size, tall crowns, moderately to very complex fossette plications, isolated protocones (except in heavily bsent hypoconal lakes, strong parastyles and mesostyles, weakly educed P2 anterostyles (Figure 2, Table 1). Adult lower cheek teeth ( $n=21$, exhibited small size, very tall crowns, widely separated rounded or angu (penetrating isthmus) ectofflexids, protostylids absent, and rudimentary bsent pil caballinids (Figures 3,4 ). Metapodials are very small and long Cheek tooth a the hipparionines Cormohipparion, Hipparion, Neohipparion, MacFadden, 1984; MacFadden and Waldrop, 1980). Observed exclude N. westoni, N. morgani, and N. aztecus (Hulbert, 1993). Three characters (cheek tooth crown height, metapodial elongation,
presence of protostylids) are significant in distinguishing Nannippus species The develop from Hemphillian N. Ienticularis to medial Blancan N. beckensis to early-late Blancan N. Peninsulatus.
The RSR-1 adult upper cheek teeth do not exhibit greater crown heig than Nannippus beckensis (Table 2). RSR-1 adult lower cheek teeth, 2). The maximum crown height of lightly worn adult lower cheek teeth from Uell beyond the maximum observed in N. beckensis and N. Ienticularrs
(Table 2; Dalquest and Donovan; 1973; MacFadden, 1984). No RSR-1 adu

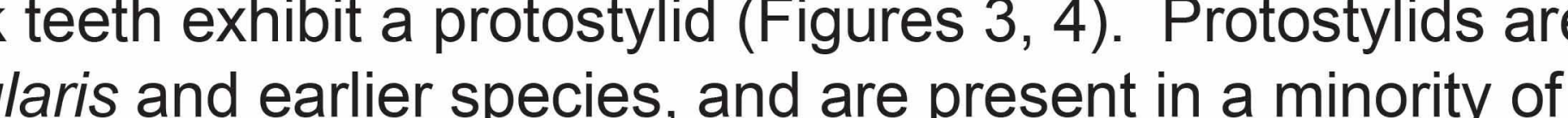
eckensis specimens (Figure 3; Dalquest and Donovan, 1973, Hulbert degree of elongation that is exclusive to $N$. peninsulatusus (Figure 5 . The The
suite of observed characters identifies the RSR- 1 hipparion as N.

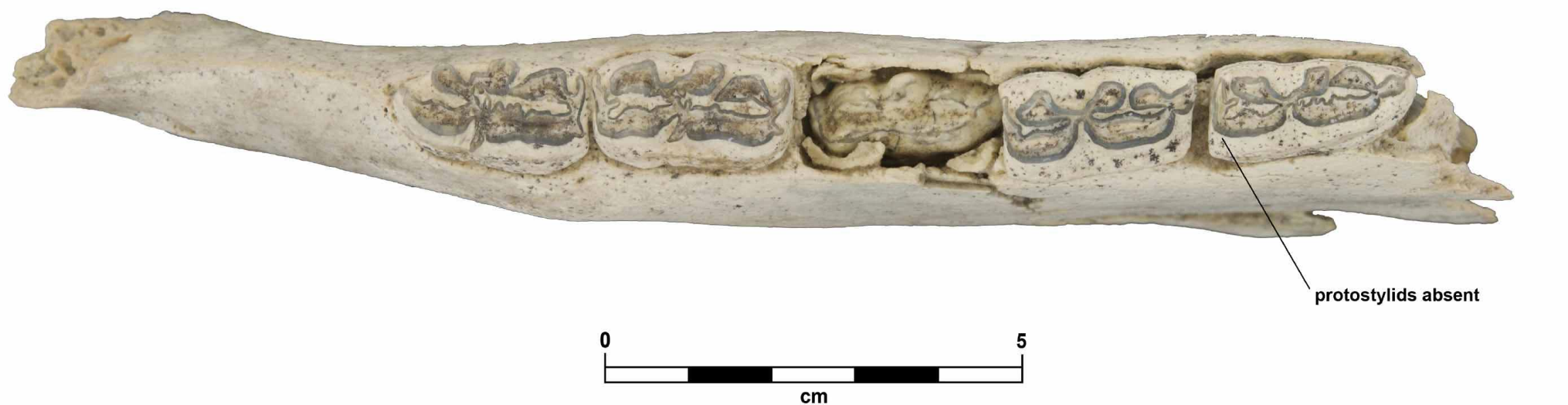

Figure 5. Bivariate plot of metacarpal (left) and metatarsal (right) leng
width for Nannippus peninsulatus, N. beckensis, and N. lenticularis.

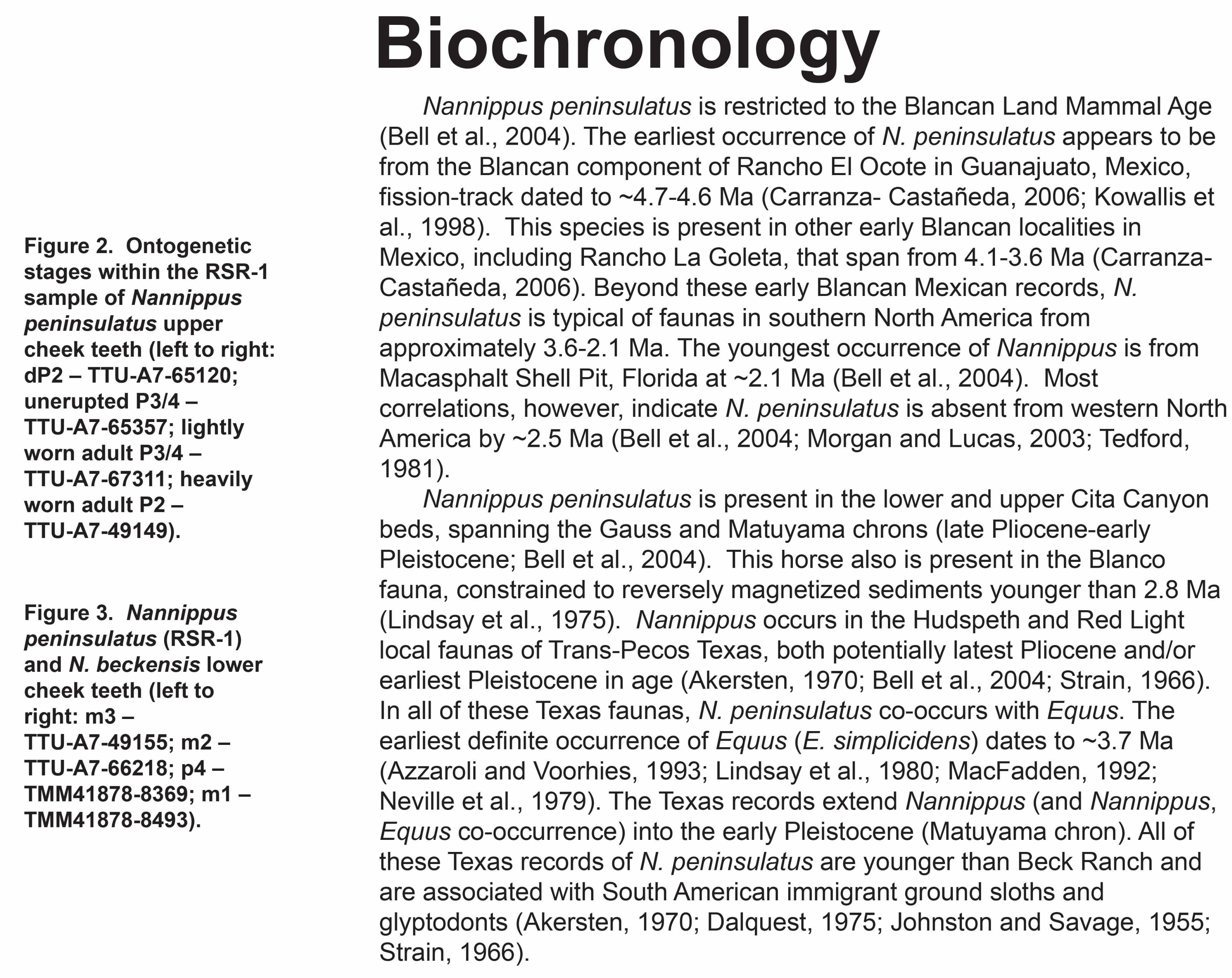

Figure 4. RSR-1
Nannippus penins

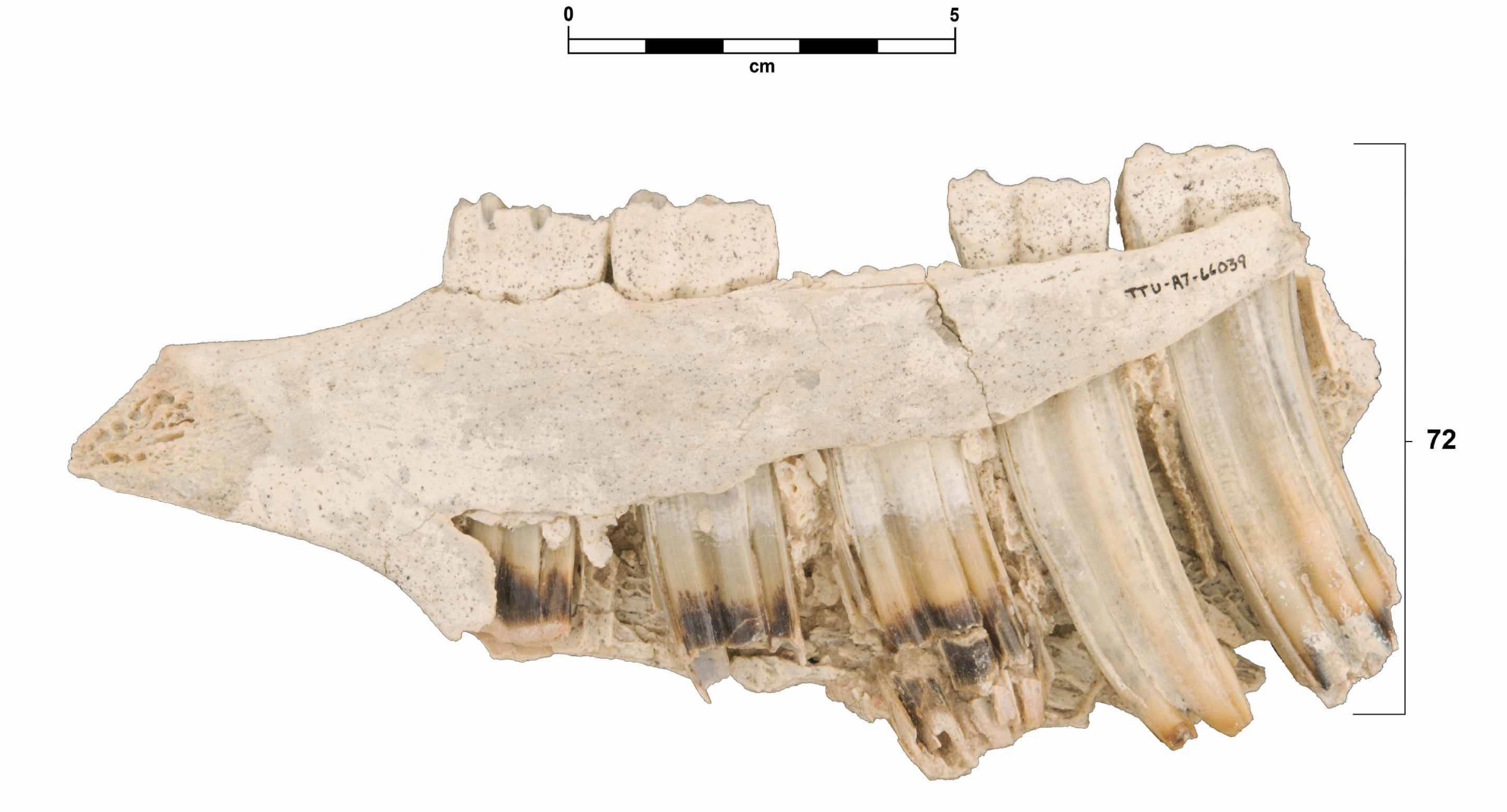

right mandible segmens
Note very high crown
$(72 \mathrm{~mm})$ and absence of $(72 \mathrm{~mm})$ and a.
protostylids.

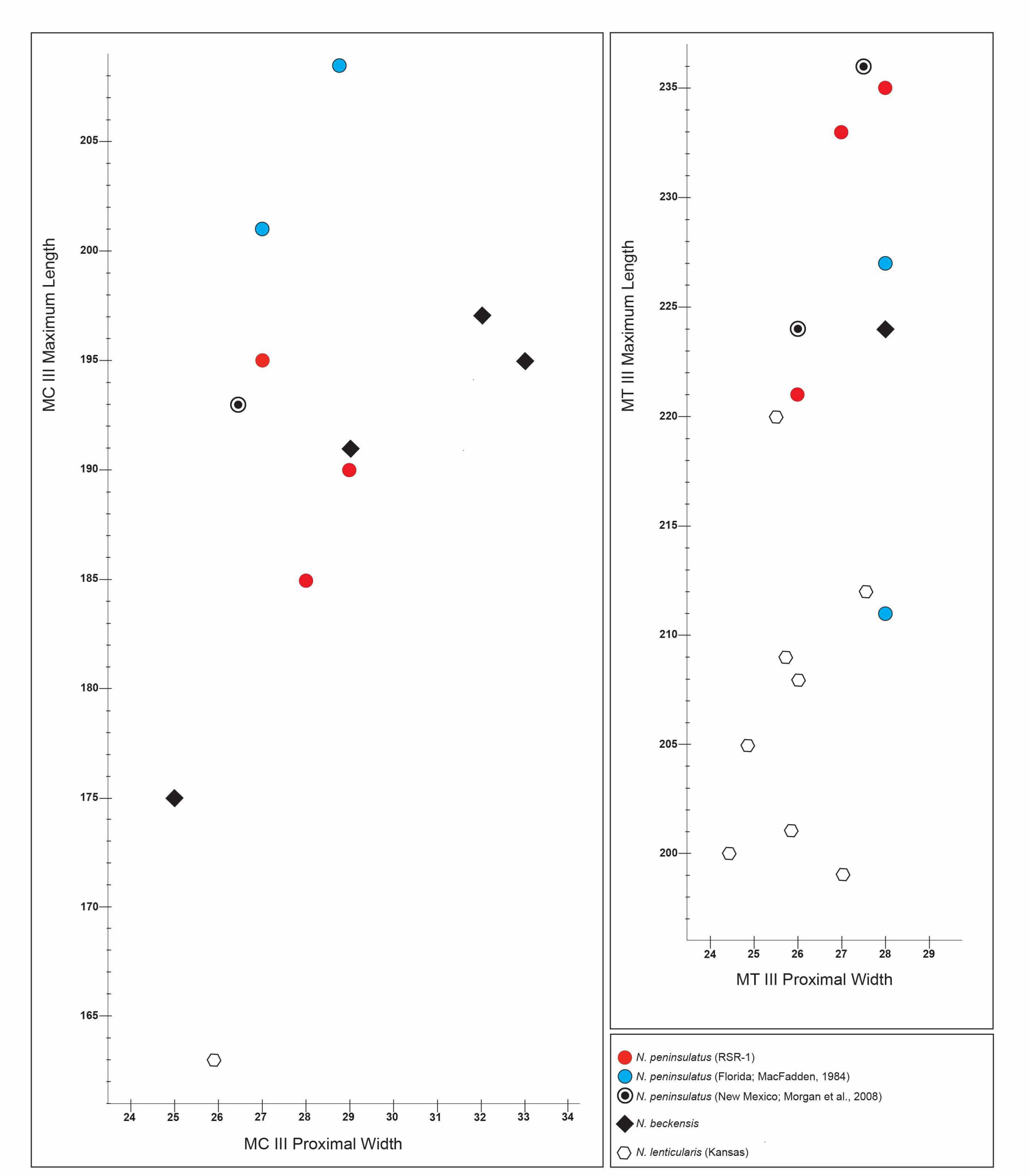

\section{Conclusions}

The small RSR-1 hipparion is identifified as Nannippus peninsulatus
based on crown height, absence of protostylids, and metapodial elongation. Co-occurrence of Equus and $N$. peninsulatus indicates RSR-1 is younger

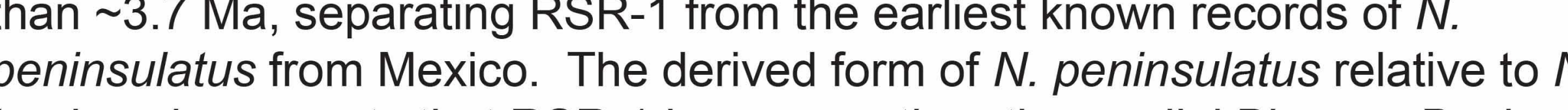
beckensis suggests that RSR-1 is younger than the medial Blancan Beck
Ranch ( $\sim .3 .5 \mathrm{Ma})$. Presence of $N$. peninsulatus constrains the age of RSR-1
to between $3.5-2.1$ Ma.

Acknowledgments

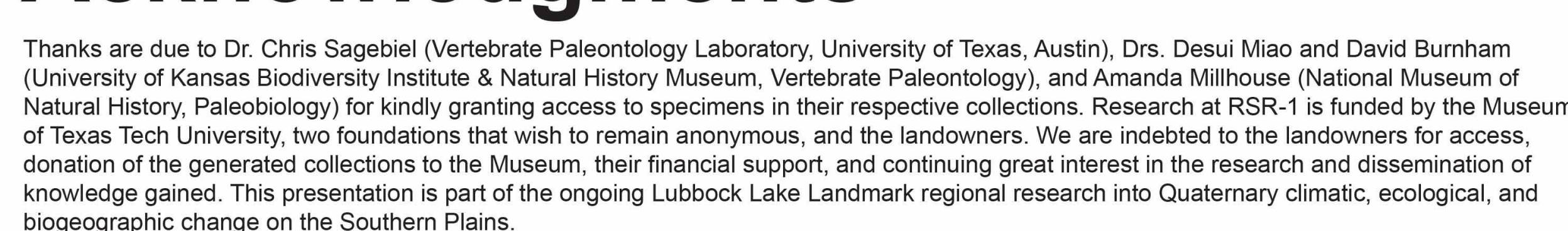

References

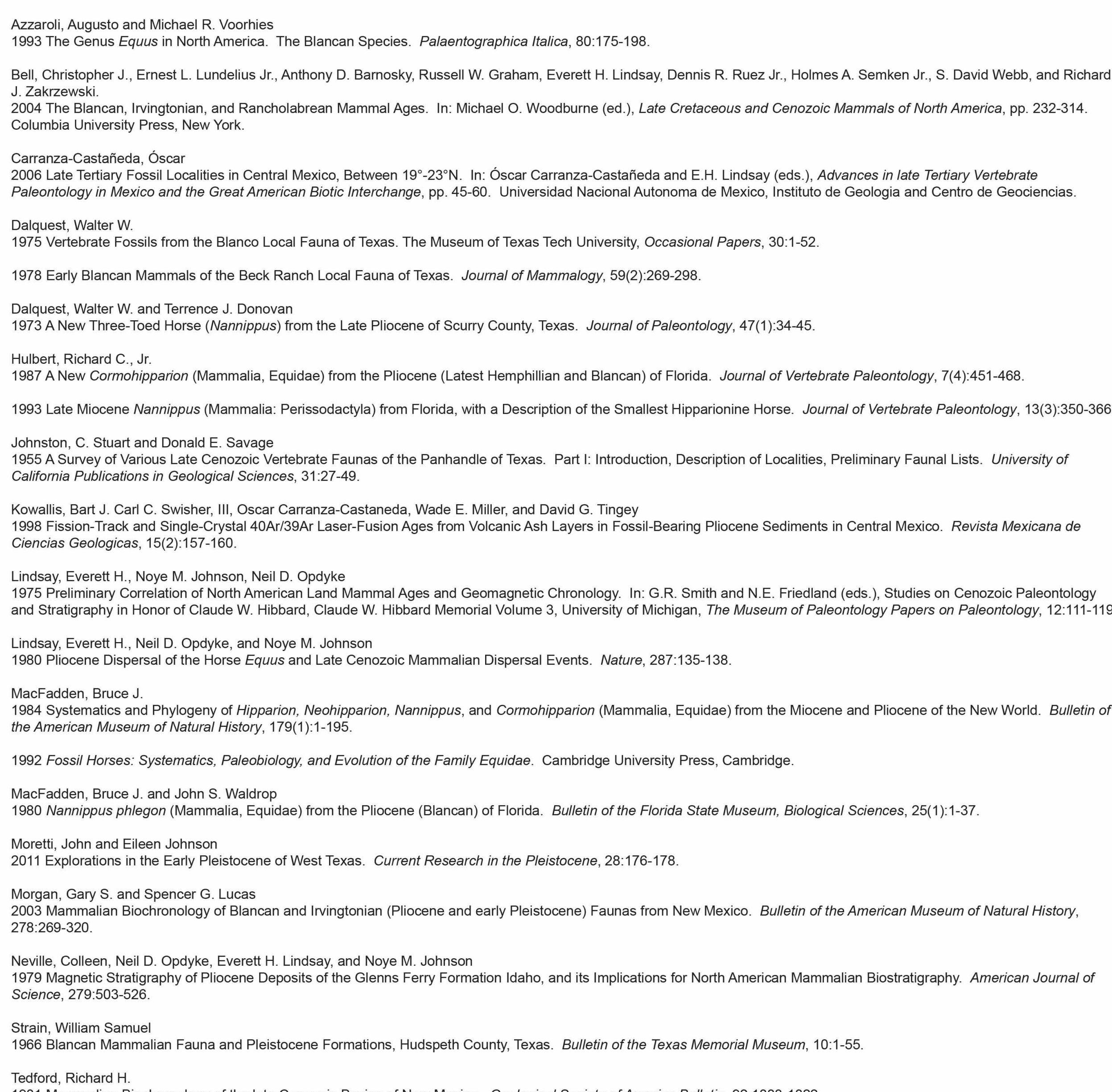

